\title{
Actualización de conocimientos en diálisis. Aplicación de un nuevo método de capacitación profesional
}

\author{
Ernestina Junyent Iglesias, Nuria Pujolar Fulquet, Tai-Mooi Ho Wong
}

\section{Servicio de Nefrología. Hospital del Mar. Parc de Salut Mar. Barcelona}

\section{Introducción:}

Es indispensable que las enfermeras de Diálisis incorporen y mantengan conocimientos y habilidades para proporcionar cuidados de calidad. Hasta ahora en nuestra Unidad de Diálisis se realizaba formación reglada a las enfermeras de nueva incorporación, sesiones mensuales y talleres sobre nuevas técnicas. Este sistema nos proporcionaba formación sin evaluar el nivel de competencia de cada profesional ni del grupo. Necesitábamos un método de capacitación profesional que nos permitiera medir los conocimientos y habilidades de forma continuada y los corresponsabilizara de su formación. Así, decidimos aplicar el Método ILU de la filosofía LEAN, en Diálisis. Método ILU es una herramienta de fácil comprensión y aplicable a cualquier ámbito profesional, permitiendo medir los conocimientos y clasificarlos en tres niveles de competencia:

- I puede realizar el procedimiento con supervisión.

- L puede realizar el procedimiento sin supervisión, de forma autónoma.

- U autónoma y capaz de formar a otros profesionales.

Nuestro objetivo de capacitación, es que todas las enfermeras de nuestra Unidad obtengan el nivel L.

Fases:

- Preparación:

- Definición de las técnicas y cuidados de enfermería (TCE) que conforma nuestra cartera de servicio, 10 técnicas de HD y 6 técnicas de DP.

- Autoevaluación de las enfermeras en cada uno de los apartados de la cartera de servicio, con los resultados elaboración del mapa del conocimiento individual y por turnos.
- Validación

- Formación y evaluación de las enfermeras formadoras designadas entre las que se auto valoran "U".

- Evaluación de las enfermeras en las TCE en los que se auto valoran " $\mathrm{L}$ ".

- Formación mediante talleres y valoración de las enfermeras que se auto valoran "I".

\section{Resultados:}

Se autoevaluaron 32 enfermeras con una edad media de $37,8( \pm 8,9)$ años y una experiencia mediana en Diálisis de $10(2 ; 30)$ años.

$11(34,4 \%)$ trabajan en turno de mañana, 8 (25\%) en turno de tarde, 4 (12,5\%) como suplentes de día y $9(28,1 \%)$ en turno de noche.

El resultado de las autoevaluaciones en Hemodiálisis fue:

- $5(15,6 \%)$ se valoraron nivel $L / U$ en todas las técnicas.

- $27(84,4 \%)$ se valoraron nivel L/U en alguna técnica.

En Diálisis Peritoneal:

- $6(18,75 \%)$ se valoraron nivel L/U en todas las técnicas.

- $26(81,25 \%)$ se valoraron nivel L/U en alguna técnica.

Durante 6 meses se formaron y fueron evaluadas con una prueba escrita, con los siguientes resultados:

- Hemodiálisis.

- $25(78,1 \%)$ validaron "L" en todas las TCE.

- $9(28,1 \%)$ validaron "U2 en alguna TCE. 
- Diálisis Peritoneal.

- $29(90,6 \%)$ validaron "L" en todas las TCE.

- $2(6,25 \%)$ validaron "U" en todas las TCE.

\section{Conclusiones:}

El método ILU:

- Obliga a definir la cartera de servicios de la unidad.

- Estandariza el nivel de competencia exigible.

- Ayuda a realizar un plan de formación individualizado y dirigido a las necesidades de la unidad.

- Corresponsabiliza a los profesionales en su propia formación y potencia su implicación.

- Disponer de un mapa del conocimiento es muy útil para decidir la formación del grupo así como en la programación de los turnos en periodos festivos.

\section{Referencias Bibliográficas}

1. URL:http://w27.bcn.cat/porta22/images/es/11_ Gestion_del_Conocimiento_ES_Intranet_P22_ tcm24-3825.pdf.

2. URL: http://www.institutolean.org/index.php/acerca/que-es-lean.

3. URL:http://www.auren.es/scripts/downloadarchivo.aspx?idelemento 708 .
4. URL:http://www.researchgate.net/publication/46531895_Manufactura_Esbelta_(Lean_Manufacturing)._Principales_Herramientas.

5. Fernández Collado E. La generación de conocimiento enfermero y su gestión en las divisiones de enfermería. Una propuesta estratégica. Educare21 2007; 37. Disponible en: http://www. enfermeria21.com/educare/ (Consultado abril 2012).

6. URL:http://www.auren.es/scripts/downloadarchivo.aspx?idelemento 708.

7. Lean healthcare, un camí a l'excellència. Disponible en: http://clinicabofill.net/activitats/Article_ Raul\%200rtega.pdf (Consultado feb.2012).

8. Govindarajan R. El desorden sanitario tiene cura. Desde la seguridad del paciente hasta la sostenibilidad del sistema sanitario con la gestión por procesos. Barcelona: Marge Médica Books. 2009. Pag 99-112.

9. Mejorando la seguridad del paciente en los hospitales: De las ideas a la acción. Aprendizaje organizativo. P 12-14. Disponible en: http://www. msc.es/organizacion/sns/planCalidadSNS/docs/ Mejorando_Seguridad_Paciente_Hospitales. pdf(Consultado feb.2012). 